\title{
ANSIETAS MENGHADAPI UJIAN NASIONAL PADA SISWA SMP DAN SMA
}

\author{
Irra Wiryani ${ }^{*}$, Ice Yulia Wardani ${ }^{2}$
}

1. Program Studi Sarjana, Fakultas Ilmu Keperawatan Universitas Indonesia, Depok 16424, Indonesia

2. Fakultas Ilmu Keperawatan Universitas Indonesia, Depok 16424, Indonesia

*E-mail: irraW08@gmail.com

\begin{abstract}
Abstrak
Ujian nasional (UN) yang diadakan pemerintah setiap tahun menimbulkan masalah ansietas bagi para siswa SMP dan SMA. Penelitian ini bertujuan mengidentifikasi gambaran tingkat ansietas siswa menghadapi ujian nasional pada siswa SMP dan SMA. Desain penelitian deskriptif dengan melibatkan 83 siswa SMPN dan 80 siswa SMAN yang akan menghadapi UN. Instrumen yang digunakan adalah modifikasi wetside test anxiety scale. Hasil penelitian didapatkan $11 \%$ siswa SMPN ansietas tingkat sedang sampai dengan berat dan 39,2\% siswa SMAN ansietas pada tingkat sedang sampai dengan berat. Perawat sekolah perlu melakukan intervensi untuk mengurangi ansietas siswa di sekolah terutama menjelang UN. Diharapkan pihak sekolah dan orang tua dapat meningkatkan perhatiannya terhadap masalah psikologis siswa.
\end{abstract}

Kata kunci: ansietas, ujian nasional, siswa

\section{Abstract}

The Anxiety of Junior High School and Senior High School Students Toward National Exam. National Exam held by government evoked anxiety problem among students. Junior and Senior High School students are the majority participant who shows anxiety problem. This research is aimed to identify the description of student's level anxiety who will encounter the National Exam in SMPN and SMAN at Depok. This study used description survey involving 83 Junior School students and 80 Senior School students. To measure the level of anxiety among students was used Wetside test anxiety scale. The result shows $11 \%$ of Junior School students identified anxiety in moderate to severe scale, and 39.2\% Senior School students shows anxiety level from moderate to panic scale. This result indicates despite the majority result of student's level of anxiety in mild scale, nursing intervention is required to reduce the level of anxiety among students, especially for students who will encounter National Exam and being identified in the level of anxiety at moderate to panic scale. The teachers and parents is expected to provide more attention to student's psychological problems.

Key words: anxiety, national final exam, students

\section{Pendahuluan}

Remaja awal merupakan masa yang berisiko mengalami depresi, tetapi pada masa ini juga memiliki pengalaman ansietas yang rendah (Mclaughlin \& King, 2015). Berbeda dengan remaja awal, remaja akhir yang merupakan masa persiapan menuju dewasa, terjadi peningkatan kemampuan berfikir. Pada masa ini risiko terjadi peningkatan ansietas seiring dengan meningkatnya tuntutan sebagai remaja akhir (Yen, et al., 2010).
Selama masa perkembangannya remaja akan melalui proses belajar di sekolah termasuk evaluasi pembelajaran. Di Indonesia dikenal dengan Ujian Nasional (UN). Peristiwa ini menimbulkan stress bagi siswa karena ketakutan tidak lulus. Salah satu bentuk respon stres adalah ansietas (Vitasari, Wahab, Othman, \& Awang, 2010). Ansietas siswa dalam menghadapi ujian merupakan masalah umum yang terjadi di setiap negara dan setiap jenjang pendidikan (Jin, et al., 2014; Karatas, 
Alci \& Aydin, 2013). Ratih, Fitriyani, dan Nurviyandari (2012) menyatakan bahwa dari 153 siswa, 109 siswa SMUN di Jakarta mengalami ansietas pada tingkat tinggi dalam menghadapi UN. Menurut Burns (2004) siswa yang memiliki harapan yang tinggi akan hasil ujian memiliki tingkat ansietas yang tinggi juga.

Beberapa penelitian menyebutkan dampak negatif ansietas pada siswa yaitu penurunan kualitas akademik, sulit berkonsentrasi selama ujian berlangsung, dan berisiko terhadap kejadian bunuh diri, serta depresi (Nguyen, et al., 2013; Yasin, \& Dzulkifli, 2011).

Penelitian tentang tingkat ansietas siswa sekolah menengah dalam menghadapi UN perlu dilakukan untuk mendapatkan fakta tentang tingkat ansietas sehingga nantinya dapat dilakukan tindakan antisipasi. Tujuan penelitian ini adalah mengidentifikasi tingkat ansietas siswa SMP, dan SMA yang akan menghadapi UN di Kota Depok.

\section{Metode}

Populasi dalam penelitian deskriptif ini adalah siswa salah satu SMPN dan SMAN yang menghadapi UN di Kota Depok. Jumlah populasi adalah 574 siswa, terdiri dari 303 siswa SMP, dan 271 siswa SMA. Jumlah responden 163 siswa, terdiri dari 83 siswa SMP dan 80 siswa SMA. Responden ini diplih dengan simple random sampling.

Instrumen yang digunakan Wetside test anxiety scale oleh Driscoll (2007) yang dimodifikasi oleh Swasti, Helena, dan Pujasari (2011). Instrumen dengan skala Likert ini terdiri dari 10 pertanyaan (Driscoll, 2007). Variabel lain yang diukur adalah karakteristik individu seperti jenis kelamin, jenjang pendidikan, keikutsertaan bimbel, pendidikan orang tua, dan penghasilan orang tua.

Pengambilan data yang dilakukan dengan memerhatikan aspek etik. Pengolahan data yang dilakukan dengan bantuan perangkat lunak komputer.

\section{Hasil}

Rerata usia siswa SMP 14 tahun (95\% CI). Tingkat ansietas siswa SMA dari 82 siswa $89 \%$ teridentifikasi ansietas ringan, dan $11 \%$ ansietas sedang sampai berat. Rerata usia siswa SMA 17 tahun $(95 \%$ CI). Frekuensi tingkat ansietas siswa SMA dari 74 siswa $60,8 \%$ teridentifikasi ansietas ringan, dan 39,2\% ansietas sedang sampai panik. Tingkat ansietas siswa SMPN dan SMAN menurut karakteristik individu seperti usia, jenis kelamin, keikutsertaan bimbel, pendidikan orang tua, dan penghasilan orang tua dapat dilihat di table 1 dan 2.

Tabel 1. Tingkat Ansietas Menurut Karakteristik Siswa SMP

\begin{tabular}{|c|c|c|c|c|}
\hline \multirow[t]{2}{*}{ Variabel } & \multicolumn{2}{|c|}{$\begin{array}{c}\text { Ansietas } \\
\text { Ringan }\end{array}$} & \multicolumn{2}{|c|}{$\begin{array}{c}\text { Ansietas } \\
\text { Sedang-Berat }\end{array}$} \\
\hline & $\mathbf{n}$ & $\%$ & $\mathbf{n}$ & $\%$ \\
\hline \multicolumn{5}{|l|}{ Jenis Kelamin } \\
\hline Laki-laki & 32 & 86,5 & 5 & 13,5 \\
\hline Perempuan & 41 & 91,2 & 4 & 8,8 \\
\hline \multicolumn{5}{|l|}{ Keikutsertaan Bimbel } \\
\hline Mengikuti & 71 & 88,7 & 9 & 11,3 \\
\hline Tidak Mengikuti & 2 & 100 & - & - \\
\hline \multicolumn{5}{|l|}{ Pendidikan orang tua } \\
\hline SMA & 1 & 100 & - & - \\
\hline Perguruan Tinggi & 72 & 88,9 & 9 & 11,1 \\
\hline \multicolumn{5}{|l|}{ Penghasilan orang tua } \\
\hline$\leq \mathrm{UMK}$ & 1 & 100 & - & - \\
\hline$\geq \mathrm{UMK}$ & 72 & 88,9 & 9 & 11,1 \\
\hline
\end{tabular}


Tabel 2. Tingkat Ansietas Menurut Karakteristik Siswa SMA

\begin{tabular}{lcccc}
\hline \multirow{2}{*}{ Variabel } & \multicolumn{2}{c}{$\begin{array}{c}\text { Ansietas } \\
\text { Ringan }\end{array}$} & \multicolumn{2}{c}{$\begin{array}{c}\text { Ansietas } \\
\text { Sedang-Panik }\end{array}$} \\
\cline { 2 - 5 } & n & $\%$ & n & $\%$ \\
\hline Jenis Kelamin & & & & \\
Laki-laki & 15 & 50 & 15 & 50 \\
Perempuan & 30 & 68,2 & 14 & 31,8 \\
& & & & \\
Keikutsertaan Bimbel & & & & \\
Mengikuti & 42 & 63,6 & 24 & 36,4 \\
Tidak Mengikuti & 3 & 37,5 & 5 & 62,5 \\
& & & & \\
Pendidikan orang tua & & & & \\
$\begin{array}{l}\text { SD } \\
\text { SMP }\end{array}$ & 1 & 100 & - & - \\
SMA & 1 & 100 & - & - \\
Perguruan Tinggi & 14 & 77,8 & 4 & 22,2 \\
& 29 & 53,7 & 25 & 46,3 \\
Penghasilan orang tua & & & & \\
$\leq$ UMK & 6 & 60 & 4 & 40 \\
$\geq$ UMK & 39 & 60,9 & 25 & 39,1 \\
\hline
\end{tabular}

\section{Pembahasan}

Hasil penelitian menunjukkan rerata usia responden SMPN adalah berusia 14 tahun. Beberapa hasil penelitian menjelaskan bahwa usia tidak memengaruhi tingkat ansietas siswa (Patience \& Chinyere, 2014). Hal ini sesuai dengan hasil penelitian pada siswa SMPN, yang mayoritas memiliki ansietas ringan, dan tergolong dalam usia remaja awal. Menurut Basavanthappa (2007) individu dengan ansietas ringan akan belajar lebih kreatif dan berusaha mencari solusi permasalahannya. Pola pemikiran remaja awal masih banyak dipengaruhi masa kanak-kanak, bersikap labil, dan belum sepenuhnya memikirkan masa depan sehingga tidak merasa cemas.

Hasil penelitian ini menunjukkan tidak adanya perbedaan tingkat ansietas laki-laki dan perempuan. Hasil ini sesuai dengan penelitian Ghaderi, Kumar, dan Kumar (2009), yang menemukan bahwa laki-laki dan perempuan memiliki pengalaman depresi, stress dan ansietas yang sama. Namun, hasil penelitian ini bertolak belakang dengan penelitian Hosseini dan
Khazali (2013) yang menyebutkan adanya perbedaan tingkat ansietas antara laki-laki dan perempuan.

Mayoritas siswa yang mengikuti bimbel berada pada ansietas ringan. Hasil ini dapat dipahami karena bimbel dewasa ini dianggap sebagai kegiatan belajar yang umum dilakukan untuk mempersiapkan siswa mengikuti UN. Ini sesuai dengan beberapa studi yang menyebutkan bahwa persiapan belajar yang baik sebelum ujian dapat membantu kesulitan siswa dalam pelajaran yang secara tidak langsung berkontribusi mengurangi \& ansietas (Burns, 2004; Vitasari, et al., 2010). Program bimbel juga membantu mengurangi stres keluarga terutama dalam bidang akademik dan membantu siswa yang mengalami kesulitan belajar (Cosden, Morrison, Gutierrez, \& Brown, 2004; Hisrich, 2010).

Penelitian ini menemukan bahwa siswa dengan orang tua berpendidikan perguruan tinggi mayoritas berada pada tingkat ansietas ringan. Hal ini sesuai dengan studi Akar, Akpolat, dan Miman (2014). Orang tua yang berpendidikan tinggi akan memberikan solusi dan informasi yang lebih tepat terhadap permasalahan anak dan memberikan suasana positif dibandingkan dengan orang tua berpendidikan rendah. Menurut Li dan Prevatt (2008), suasana yang positif dalam keluarga akan bermanfaat menurunkan tingkat ansietas.

Penelitian Chen (2012) menjelaskan bahwa orang tua di China menekankan etika kesuksesan, yaitu tingkat kesuksesan anak harus lebih dari orang tuanya. Ini mengakibatkan anak dituntut belajar lebih keras yang berdampak pada ansietas di sekolah. Pendidikan orang tua yang tinggi dapat diartikan sebagai tekanan atau tuntutan kepada anaknya yang juga tinggi. Oleh karena itu, penelitian ini menggambarkan bahwa pendidikan orang tua tidak berkontribusi besar dalam tingkat ansietas kategori sedang sampai dengan berat.

Hasil penelitian ini menunjukkan bahwa siswa 
dengan penghasilan orang tua di atas UMK, berada pada ansietas ringan. Penghasilan orang tua tidak sepenuhnya berkontribusi dalam masalah ansietas pada tingkat sedang sampai dengan berat karena mayoritas siswa yang memiliki orang tua berpenghasilan yang lebih tinggi mayoritas mengalami ansietas ringan. Pendapatan keluarga memengaruhi motivasi belajar dan proses belajar siswa di sekolah yang berdampak pada tingkat ansietas siswa, sehingga pendapatan keluarga harus cukup agar prestasi akademik meningkat dan ansietas berkurang (Yousefi, et al., 2010). Sebaliknya, siswa dengan keluarga berpenghasilan rendah tidak hanya mempunyai masalah di sekolah tetapi juga di rumah (Wade \& Tavris, 2008).

Tekanan orang tua agar siswa lulus dengan prestasi yang memuaskan, sehingga mendapat tempat di perguruan tinggi favorit, tingginya persaingan untuk memasuki dunia kerja dan persiapan untuk hidup mandiri terpisah dari orang tua merupakan sumber ansietas siswa yang berusia remaja akhir atau yang berpendidikan SMA (Karatas, Alci, \& Aydin, 2013; Santrock, 2007; Yen, et al., 2010). Akan tetapi, hasil penelitian ini menunjukkan bahwa mayoritas siswa SMA hanya mengalami anisetas ringan. Kondisi berbeda ini mungkin saja terjadi karena sifat ansietas itu yang fluktuatif.

Berdasarkan jenis kelamin, tampak siswa laki-laki lebih banyak yang mengalami ansietas sedang sampai panik dibanding perempuan. Hasil ini sesuai dengan penelitian Revina, Marslin, Franklin, dan Sheeba (2014) di India, tetapi bertolak belakang dengan penelitian Syokwaa, Aloka dan Ndunge (2014). Menurut Revina, Marslin, Franklin, dan Sheeba (2014) di India orang tua menuntut semua anak laki-lakinya untuk memiliki pekerjaan dengan penghasilan dan jabatan tinggi sehingga menyebabkan laki-laki lebih cemas.

Penelitian mengenai tingkat ansietas dikaitkan dengan jenis kelamin ini menunjukkan hasil yang belum konsisten. Hal ini dapat terjadi mengingat respon terhadap ansietas juga berbeda. Santrock (2007), berpendapat bahwa la- ki-laki memiliki sikap menyangkal dibandingkan perempuan dalam merespon secara emosional saat mengalami stres.

Berdasarkan keikutsertaan bimbel, siswa SMAN yang mengikuti bimbel mayoritas mengalami ansietas ringan, walaupun yang mengalami ansietas sedang sampai dengan panik juga cukup banyak. Hasil penelitian Donaldson (2013) tidak menunjukkan bahwa siswa yang melakukan persiapan seperti bimbel lebih baik dibanding siswa yang tidak melakukan persiapan sebelum ujian. Kegiatan bimbingan belajar dapat secara efektif membantu siswa jika didukung oleh tenaga pengajar yang berkualitas dan jumlah siswa per kelas yang lebih sedikit dibandingkan kelas di sekolah (McMillon, 2004). Bimbingan belajar diadakan untuk membantu siswa yang mengalami kesulitan belajar dan membantu siswa meningkatkan prestasi di sekolah. Pemilihan program bimbel yang tepat berpengaruh terhadap keberhasilan siswa (Hisrich, 2010).

Siswa SMA dengan orang tua berpendidikan perguruan tinggi masih ada yang mengalami ansietas sedang sampai panik, bahkan hampir dari setengahnya. Ini berbeda dengan pandangan Hong dan Park (2012), yang mengatakan bahwa keluarga dengan pendidikan yang lebih tinggi akan memberikan pengalaman yang lebih baik terhadap anak-anaknya, memberikan kehangatan, keyakinan terhadap kemampuan akademik anak dan ikut terlibat dalam pembelajaran anak. Hal ini sesuai dengan penelitian Jin, et al., (2014) dan Chen (2012). Penelitian lainnya menemukan hal yang berbeda yaitu pendidikan orang tua tidak berpengaruh pada ansietas siswa yang akan menghadapi ujian (Revina, et al., 2014; Swasti, et al., 2011).

Hasil penelitian ini tidak menggambarkan semakin tingginya pendidikan orangtua maka tingkat ansietas kategori sedang sampai panik semakin sedikit pula. Ada faktor lain menjadi pertimbangan seperti dikatakan oleh Deb, Chatterjee, dan Walsh (2010) yaitu remaja yang tidak memiliki waktu yang berkualitas dengan orang tua tidak memperlihatkan ke- 
nyamanan ketika berbagi masalah pribadi dengan orang tuanya. Tidak adanya kedekatan antara orang tua membuat anak hanya menyimpan permasalahannya sendiri sehingga ansietas meningkat.

Hampir seluruh siswa dengan orang tua berpenghasilan di bawah UMK mengalami ansietas sedang sampai panik. Akar, et al., (2014), menjelaskan siswa dengan keluarga berpenghasilan rendah memiliki tingkat ansietas yang tinggi dibandingkan dengan siswa dengan orang tua berpenghasilan tingi. Menurut Kumaraswamy (2013), keluarga dengan penghasilan rendah lebih sering terpapar dengan stres. Siswa tidak hanya mempunyai masalah di sekolah saja tetapi juga di rumah. Thomas (2005) juga menyimpulkan bahwa keluarga berpenghasilan rendah memengaruhi tingkat ansietas dan prestasi akademik siswa.

Hasil penelitian ini membuka wawasan tentang pentingnya penempatan tenaga kesehatan, khususnya perawat di area sekolah. Seorang perawat dapat melakukan asuhan yang komprehensif, tidak hanya fisik atau kondisi sakit. Perawat sekolah seharusnya melakukan tindakan untuk mengatasi masalah psikologis remaja khususnya ansietas, sehingga permasalahan yang lebih kompleks dapat dicegah dan diantisipasi.

\section{Kesimpulan}

Penelitian ini menyimpulkan bahwa mayoritas siswa SMP dan SMA mengalami ansietas pada tingkat ringan, tetapi masih terdapat ansietas pada tingkat sedang bahkan sampai dengan panik, khususnya siswa SMA. Karakteristik siswa seperti usia, jenis kelamin, keikutsertaan bimbel, pendidikan dan penghasilan orang tua dapat menjadi latar belakang tingkat ansietas siswa. Adanya tuntutan orang tua terhadap anak, pemilihan program bimbel tingkat kecerdasan siswa, kualitas dan kuantitas waktu orang tua dan anak dapat menjadi faktor kemungkinan yang memengaruhi ansietas siswa. Penelitian selanjutnya diperlukan untuk menguji hubungan antara berbagai faktor dengan tingkat ansietas siswa sekolah. Penelitian berikutnya lebih ke arah pengembangan berbagai metode atau intervensi untuk menyelesaikan masalah yang berkaitan dengan ansietas siswa sekolah. Hasil penelitian ini juga merekomendasikan kepada berbagai pihak yang terkait dengan anak sekolah, seperti pengelola pendidikan, orang tua, masyarakat umum dan bahkan pemerintah untuk lebih memperhatikan aspek psikologis anak (MK, INR, AR).

\section{Referensi}

Akar, A., Akpolat, D., \& Miman, M.. (2014). Trait anxiety level analysis of high school students with migration in Mersin. Procedia-social and behavioral sciences, 113, 143-150. doi: 10.1016/j.sbspro.2014.01.021

Basavanthappa, B.T. (2007). Psychiatric mental health nursing (1st Ed.). New Delhi: Jaypee Brother Medical Publisher

Burns, J.D. (2004). Anxiety at the time of the final exam: Relationships with expectations and performance. Journal of Education for Business, 119-124. Diperoleh dari http://eric. ed .gov/?id=EJ745247

Chen, H. (2012). Impact of parent's socioeconomic status on perceived parental pressure and test anxiety among Chinese high school students. International Journal of Psychological Studies, 4 (2), 235-245. doi: http://dx.doi.org/10.5539/ ijps.v4n2p235

Cosden, M., Morrison, G., Gutierrez, L, \& Brown, M. (2004). The effects of homework and after-school activities on school success. Theory into Practice, 43 (3), 220-226. Diperoleh dari http://eric.ed.gov/?id=EJ683351

Deb, S., Chatterjee, P., \& Walsh, K.M., (2010). Anxiety among high school students in India: Comparisons across gender, school type, social strata and perceptions of quality time with parents. Australian Journal of Educational \& Developmental Psychology, 10, 18-31. Diperoleh dari http://eprints.qut.edu.au/33012/ 
Donaldson, R.F. (2013). Survey of college entrance exam preparation methods (Doctoral Dissertations, Liberty University). Lynchburg, VA: Liberty University Diperoleh dari http://search.proquest.com/docview/13622562 60 ? accountid $=17242$

Driscoll, R. (2007). Westside test anxiety scale validation. Diperoleh dari http://www.amtaa. org/scalewest.html_

Ghaderi, A.R., Kumar, V., \& Kumar, S. (2009). Depression, anxiety and stress among the Indian and Iranian students. Journal of indian academic of applied psychology, 1 (35), 33-37.

Hisrich, K.E. (2010). Using internet polls to understand student perspectives for school improvement: An exploration of adolescents' views on tutoring (Doctoral Dissertations, Arizona State University). United States: Arizona State University Libraries. Diperoleh dari http://search.proquest.com/docview/82046 8739? accountid $=17242$

Hong, S.C., \& Park, Y.S. (2012). An analysis of the relationship between self-study, private tutoring, and self-efficacy on self-regulated learning. KEDI Journal of Educational Policy, 9 (1), 113-144. Diperoleh dari https://www. researchgate.net/publication/262374099_An_a nalysis_of_the_relationship_between_self-stud y_private_tutoring_and_self-efficacy_on_selfregulated_learning

Hosseini, L., \& Khazali, H. (2013). Comparing the level of anxiety in male \& female school students. Procedia-sosial and behavioral science, 84, 41-46. doi:10.1016/j.sbspro.2013. 06.506

Jin, Y., He, L., Kang, Y., Chen, Y., Lu, W., Ren, X., . . . Yao, Y. (2014). Prevalence and risk factors of anxiety status among students aged 13-26 years. Int J Clin Exp Med, 7 (11), 4420-4426. Diperoleh dari http://www.ncbi. nlm.nih.gov/pmc/articles/PMC4276221/

Karatas, H., Alci, B., \& Aydin, H. (2013). Correlation among high school senior students' test anxiety, academic performance and points of university entrance exam. Educational
Research and Reviews, 8 (13), 919-926. doi: http://dx.doi.org/10.5897/ERR2013.1462

Kumaraswamy, N. (2013). Academic stress, anxiety and depression among college students: A brief review. International review of social sciences and humanities. 1 (5), 135-143. Diperoleh dari http://connection.ebsc ohost.com/c/articles/90540047/academic-stress -anxiety-depression-among-college-students-br ief-review

Li, H., \& Prevatt, F. (2008). Fears and related anxieties in Chinese high school students. School Psychology International, 29 (2), 89-104.

McLaughlin, K.A., \& King, K. (2015). Developmental trajectories of anxiety and depression in early adolescence. $J$ Abnorm Child Psychol, 43 (2), 311-323. Doi: 10.1007/s10802-014-9898-1

McMillon-Nelson, M. (2004). Impact of tutoring on academic achievement when administered by highly qualified teachers (Order No. 3165243). Available from ProQuest Dissertations \& Theses Global. (305127243). Retrieved from http://search.proquest.com/doc view/305127243? accountid $=17242$

Nguyen, D.T., Dedding, C., Pham, T.T., Wright, P., \& Bunders, J. (2013). Depression, anxiety, and suicidal ideation among Vietnamese secondary school students and proposed solutions: a cross-sectional study. BMC Public Health, 13(1), 1-10. Doi: 10.1186/1471-245813-1195

Patience, N.A., \& Chinyere, I.N. (2014). Appraisal of the level of the test anxiety among tertiary education student: A case of Alvan Ikoku Federal College of Education, Oweri, Imo State, Nigeria. African Educational Research Journal, 2 (1), 20-26. Diperoleh dari http://www.netjournals.org/z_AERJ_13_011.ht $\mathrm{ml}$

Ratih, NK., Fitriyani, P., \& Nurviyandari, D. (2012). Hubungan tingkat kecemasan terhadap koping siswa SMUN 16 dalam menghadapi ujian nasional. (Skripsi tidak dipublikasi). FIK-Universitas Indonesia, Depok, Jawa Barat. 
Revina, A.M., Marslin, G., Franklin, G., \& Sheeba, C.J. (2014). Test anxiety levels of board exam going students in Tamil Nadu, India. BioMed Research International. doi: http://dx.doi.org/ $10.1155 / 2014 / 578323$

Santrock, J.W. (2007). Adolescent (11th Ed.). New York City: Mc. Graw Hill Companies.

Swasti, K.G., Helena, N., \& Pujasari, H. (2011). Pengaruh terapi suportif terhadap ansietas siswa kelas XII SMA N 1 Kutasari dalam menghadapi ujian nasional. (Tesis Tidak Dipublikasi). FIK Universitas Indonesia, Depok, Jawa Barat, Indonesia

Syokwaa, K., Aloka, P., \& Ndunge, S. (2014). The Relationship between anxiety levels and academic achievement among students in selected secondary schools in Lang'ata District, Kenya. Journal Of Educational And Social Research, 4 (3), 403-413. doi: 10.5901/ jesr.2014.v4n3p403

Thomas, R.M. (2005). Comparing theories of child development. California: Thomson and Wad worth

Vitasari, P., Wahab, M.N.A., Othman, A., \& Awang, M.G. (2010). A research for identifying study anxiety sources among university students. International Education Studies. 3 (2), 189-196. Diperoleh dari http: //files .eric.ed.gov/fulltext/EJ1066077.pdf
Wade, C., \& Tavris, C. (2008). Psychology (10th Ed.). Upper Saddle River: Pearso-Prentice Hall

Yasin, M.A.S.M., \& Dzulkifli, M.A. (2011). Differences in depression, anxiety and stress between low-and high-achieving students. Journal of Sustainability Science and Management., 6 (1), 169-178. Diperoleh dari https://www.researchgate.net/publication/2877 51683_Differences_in_depression_anxiety_an d_stress_between_low-and_high-achieving_st udents

Yen, C., Ko, C., Wu, Y., Yen, J., Hsu, F., \& Yang, P. (2010). Normative data on anxiety symptoms on the multidimensional anxiety scale for children in Taiwanese children and adolescents: Differences in sex, age, and residence and comparison with an American sample. Child Psychiatry and Human Development, 41 (6), 614-623. doi: http://dx.doi.org/10.1007/s10578-010-0191-4

Yousefi, F., Redzuan, M., Bte, M., Juhari, R. B., \& Talib, M.A. (2010). The effects of family income on test-anxiety and academic achievement among iranian high school students. Asian Social Science, 6 (6), 89-93. doi: http://dx.doi.org/10.5539/ass.v6n6p89 